\title{
Application of Fuzzy Multi-Criteria Decision Making Analysis for Evaluating and Selecting the Best Location for Construction of Underground Dam
}

\author{
Parviz Rezaei $^{1}$, Kamran Rezaie ${ }^{2}$, Salman Nazari-Shirkouhi ${ }^{2}$, \\ Mohammad Reza Jamalizadeh Tajabadi ${ }^{3}$ \\ ${ }^{1}$ Roudbar Branch, Islamic Azad University, Roudbar, Iran \\ ${ }^{2}$ Department of Industrial Engineering, College of Engineering, University of \\ Tehran, Tehran, Iran \\ Email: krezaie@ut.ac.ir; snnazari@ut.ac.ir \\ ${ }^{3}$ Faculty of Natural Resources, University Of Zabol, Zabol, Iran
}

\begin{abstract}
One crisis which human beings will probably face in the upcoming decades is the water crisis. The crisis in arid and semi-arid regions covering a large part of Iran would be much more severe. Thus, using novel methods of water collection such as construction of underground dam is so important. Decision making and selection of an appropriate option in construction of such dams is one basic challenge. The major issue in construction of such dams is selecting an appropriate location. Selecting the best location for building underground dams is a challenge due to involvement of a wide range of influential factors. In this paper, analytic hierarchy process (AHP), one of multi-criteria decision making (MCDM) techniques in fuzzy environment is applied to select the optimal alternative for construction of an underground dam in a case study. Results show that using AHP in the fuzzy environment improves decision making through considering more important factors in decision making.
\end{abstract}

Keywords: underground dam; multi-criteria decision making; fuzzy theory; AHP

\section{Introduction}

Water shortage in arid and semi-arid regions is one of the problems of policy makers. Various solutions have been used to overcome this problem around the world. One of such solutions is construction and use of underground dams. In recent years, efforts have been made at national level to use dams more because of increase in severity, extent, and frequency of droughts. Thus, steps were taken quickly so as to facilitate construction of more such dams in the country. Since 
construction and operations of these dams is a new technique in water resource management in Iran, the present paper attempts to compare application of two methods of fuzzy analytic hierarchy process and analytic hierarchy process. The aim of this comparison is to familiarize experts with these methods and to specify the strengths and weaknesses of these two methods.

Underground dams are built for different purposes such as prevention of saltwater and freshwater interference (Garagunis, 1981), avoidance of underground water penetration in the mines (Gupta et al., 1987), prevention of seawater into freshwater aquifers (Onder and yilmaz, 2000), and holding water for operation (Nilsson, 1988). Underground dams are usually constructed in the bed of a water stream where signs of underground water is seen. For underground dams to be able to extract water, their construction should be justified but considering some factors as follows: bedrock depth in the water stream, water stream width, impenetrable walls, suitable sediments, the volume of useable water, suitable context for using extracted water, social issues, economic justification and so on (Nilsson, 1988). Evaluation of factors requires detailed studies to be carried out before determining initial appropriate options. Therefore, the first step in constructing underground dams is to find suitable options.

Basically, several factors influence on selection of an alternative for construction of underground dams. Taking into account all of these factors makes the decision making problem so complex. Thus, multi-criteria decision making (MCDM) methods are applied to tackle this problem.. One widely used MCDM method is the analytic hierarchy process (AHP) which has been used in various managerial areas from hydrogen production methods (Pilavachi et al., 2009) to motor cleaning systems and many others. In addition, AHP has been applied for water resource management in many studies such as Anagnostopoulos et al. (2005, 2007), Srdjevic (2007), and Mei et al. (1989). Mei et al. (1989), in applying multi-criteria decision making methods for water resource management in China, stated that analytic hierarchy process method specifies not only relative importance of each factor, but also it specifies combined weights matched to initial goal. Akpinar et al. (2005) believed that multi-criteria decision making methods are useful in planning for issues in which many factors are involved. They used this method in determining agricultural land-use types in Turkey and approved successfulness of analytic hierarchy process method in priority setting in agricultural land-use types. Montazar and Behbahani (2007) developed an optimized irrigation system selection model using analytic hierarchy process. Their findings indicated that results obtained from this model are consistent with those obtained from field evaluations. In addition, evaluation of methods showed that results provided by this model were more reliable than ordinary weighting methods. Okada et al. (2008) applied analytic hierarchy process for improvement of irrigation project. They found out that the first priority for irrigation management planners is the water delivery. In fact, they considered appropriate water allocation and control as the main factor for these planners. Montazar and Zadbagher (2010) used an 
analytic hierarchy model for assessing global water productivity in irrigation networks. They stressed that AHP is a practical and comprehensive tool for improving effectiveness of such systems.

Standard hierarchical analysis process is not effective to solve more complicated problems. Therefore, some modifications are necessary for this method. Combining fuzzy methods with analytic hierarchy process is one approach for solving the complicated problems. Fuzzy analytic hierarchy process (fuzzy AHP) has been applied in different problems as follows: in geographical information system (GIS) application (Vahidnia et al., 2008), risk evaluation of information technology projects (Iranmanesh et al., 2008), water management plans assessment (Srdjevic and Medeiros, 2008), and eco-environmental vulnerability assessment (Li et al., 2009). Kong and Liu (2005) applied fuzzy analytic hierarchical process to evaluate success factors of e-commerce. They stressed that fuzzy AHP has qualifications of both subjective and thematic factors in the decision making process. Stirn (2006) integrated the fuzzy AHP with dynamic programming approach for determining the optimal forest management decisions so that he could maximize economic, ecological and social benefits. Results indicated that this method can be successful in problems where different criteria are involved in decision making. Ascough et al. (2008) stated that decision making in natural environment is difficult due to inherent complexity of the environment and different interests of decision makers and operators. They proposed solutions to overcome this problem which are based on using fuzzy systems. They found out combining fuzzy systems with other decision making methods useful. Alias et al. (2009) applied fuzzy analytic hierarchy process for logical use of Johor River in Malaysia. The considered different dimensions of the area and concluded fuzzy method with triangular fuzzy numbers can be successful for ambiguous data. Opricovic (2011) applied fuzzy AHP with fuzzy VIKOR for water resources planning. Tsiko and Haile (2011) used GIS and fuzzy AHP in modeling optimum sites for locating water reservoirs.

Locating underground dam construction projects is a complex problem due to existence of uncertainty in factors influencing on it. Since the real world is full of ambiguities and imprecise and vague terms, most decision makers in field of underground dam construction know using linguistic terms more practical and feasible. Zadeh (1965) introduced fuzzy sets theory as a powerful tool to dominate these ambiguities, vagueness and uncertainties when there is a special complexity and lack of complete information on experts' opinions. In the current study, a useful and practical methodology is presented for group decision making on the location of underground dams construction based on the AHP and fuzzy theory.

The rest of the paper is structured as follows: Section 2 describes the proposed methodology; in Section 3 the proposed methodology is applied to locate the underground dam construction as an experiment and results are provided; in Section 4, the proposed methodology is tested for the verification and validation purposes; finally Section 5 includes conclusions of the present work. 


\section{Proposed Methodology}

In this section, the proposed fuzzy AHP based methodology is presented for evaluating and selecting the best location for underground dam construction location. The steps of the proposed methodology are illustrated in Figure 1. The steps will be implemented in a case study and described in great details.

\subsection{Fuzzy Analytic Hierarchy Process}

AHP is a decision making method for decomposing the hierarchical problem and can apply to solve a complex multi-criteria decision problem (Saaty, 1980). In the literature, AHP has widely been applied to solve the different MCDM problems. Many times decision makers are only able to provide a subjective and uncertain answer rather than an exact value (Shaw et al., 2012). Hence, such answers need to be quantified. Conventional methods of AHP cannot be used for decision making problem in the real world when fuzziness and vagueness is observed in data of problems. To handle such uncertainties and vagueness, fuzzy sets theory, initially introduced by Zadeh (1965), can be applied. Therefore, incorporation of the fuzzy concept with AHP can be more applicable and more effective than the conventional AHP in the real world problems. This issue has attracted many researchers to apply fuzzy AHP in different fields such as risk and disaster management (Takács, 2010), work safety evaluation (Zheng et al., 2012), green initiatives in the fashion supply chain (Wang et al., 2012).

Figure 1 shows the proposed fuzzy AHP based methodology for decision making on selection of the best location form underground dam construction. The steps of the proposed methodology are as follows:

\section{Step1: Determining Criteria and Alternatives and Establish hierarchal structure}

The first step of our methodology is to determine the criteria which are going to be affected for making a decision about underground dam construction location.

\section{Step 2: Collecting experts' judgments based on fuzzy scale and establish fuzzy pair-wise comparison matrices}

The sample questionnaire by Azadeh et al. (2010, 2011) and Nazari-Shirkouhi et al. (2011) can be applied to collect the experts' judgments based on fuzzy scales. In the present paper, the triangular fuzzy numbers (TFNs) for fuzzy membership function applied to enable the decision maker to make easier decisions (Kaufmann and Gupta, 1988). The membership function of a TFN is shown in Equation (1). The TFN is usually shown with $\tilde{A}=(l, m, u)$, where $l \leq m \leq u$ 


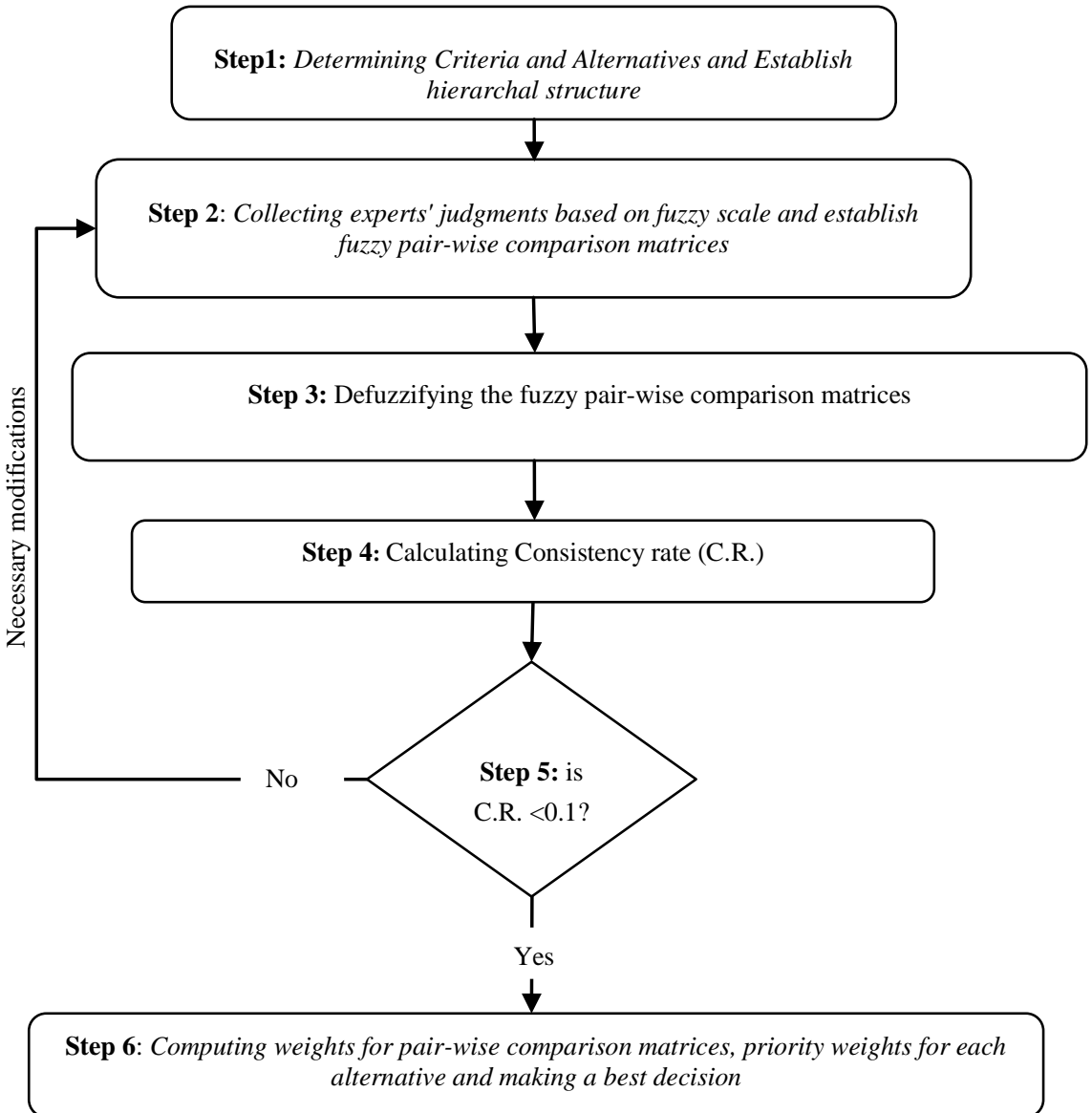

Figure 1

The proposed methodology based on fuzzy AHP

$\mu_{\tilde{A}}(x)= \begin{cases}\frac{x-l}{m-l} & l \leq x \leq m \\ \frac{u-x}{u-m} & m \leq x \leq u \\ 0 & x \prec l \text { or } x \succ u\end{cases}$

Where $-\infty \prec x \prec \infty ; \mu_{\tilde{A}}(x)$ is a continuous mapping from $R$ to the interval $[0,1]$. For two TFNs $\tilde{A}=\left(l_{1}, m_{1}, u_{1}\right) ; \tilde{B}=\left(l_{2}, m_{2}, u_{2}\right)$, some of the main mathematical operations can be expressed in equation (2) as bellow: 


$$
\begin{aligned}
& \tilde{A}+\tilde{B}=\left(l_{1}+l_{2}, m_{1}+m_{2}, u_{1}+u_{2}\right) \\
& \tilde{A}-\tilde{B}=\left(l_{1}-u_{2}, m_{1}-m_{2}, u_{1}-l_{2}\right) \\
& \tilde{A} * \tilde{B}=\left(l_{1^{*}} l_{2}, m_{1^{*}} m_{2}, u_{1^{*}} u_{2}\right) \\
& \tilde{A} / \tilde{B}=\left(l_{1} / u_{2}, m_{1} / m_{2}, u_{1} / l_{2}\right) \\
& k \tilde{A}=\left(k l_{1}, k m_{1}, k u_{1}\right), k>0, k \in R
\end{aligned}
$$

The AHP method uses pair-wise comparisons and related matrix is shown in Equation (3).

$$
\tilde{A}^{k}=\left[\tilde{a}_{i j}\right]^{k}=\begin{gathered}
C_{1} \\
C_{2} \\
\vdots \\
C_{n}
\end{gathered}\left[\begin{array}{cccc}
C_{1} & C_{2} & \ldots & C_{n}{ }^{k} \\
1 / \tilde{a}_{12} & \tilde{1} & \ldots & \tilde{a}_{1 n} \\
\vdots & \vdots & \ddots & \tilde{a}_{2 n} \\
1 / \tilde{a}_{1 n} & 1 / \tilde{a}_{2 n} & \ldots & \tilde{1}
\end{array}\right]
$$

Where, $\tilde{a}_{i j}^{k}=(1,1,1): \forall i=j ; \tilde{a}_{i j}^{k}=\frac{1}{\tilde{a}_{i j}^{k}}: \forall i \neq j$.

$\tilde{A}^{k}$ is the fuzzy judgment matrix of $k$ th expert, $\tilde{a}_{i j}^{k}$ is a the fuzzy evaluation between criterion $i$ and criterion $j$ of $k$ th expert, $\tilde{a}_{i j}=\left(l_{i j}^{k}, m_{i j}^{k}, u_{i j}^{k}\right)$.

To aggregate the experts' judgments, Buckley (1985)'s method is applied here. As is shown in equations (4-7) $l, m$, and $u$ show the minimum possible, most likely and the maximum possible value of a fuzzy number, respectively. TFN $\tilde{A}^{k}$ is defined as the following:

$$
\begin{aligned}
& \tilde{A}_{i j}=\left(l_{i j}, m_{i j}, u_{i j}\right): l_{i j} \leq m_{i j} \leq u_{i j}, l_{i j}, m_{i j}, u_{i j} \in[1 / 9,9] \\
& l_{i j}=\min \left(a_{i j k}\right) \\
& m_{i j}=\sqrt[K]{\prod_{k=1}^{K}\left(a_{i j k}\right)} \\
& u_{i j}=\max \left(a_{i j k}\right)
\end{aligned}
$$

Which, $a_{i j k}$ shows the relative importance of criteria $C_{i}$ and $C_{j}$ given by expert $k$.

The linguistic scale and underlying TFNs are illustrated in Table 1 based on Azadeh et al. (2011) and Nazari-Shirkouhi et al. (2011). 
Table 1

The linguistic scale and underlying TFN

\begin{tabular}{lll}
\hline Fuzzy number & Linguistic scales & Scale of fuzzy number \\
\hline$\tilde{1}$ & Equally important & $(1,1,1)$ \\
$\tilde{3}$ & Weakly important & $(2,3,4)$ \\
$\tilde{5}$ & Essentially important & $(4,5,6)$ \\
$\tilde{7}$ & Very strongly important & $(6,7,8)$ \\
$\tilde{9}$ & Absolutely important & $(7,8,9)$ \\
$\tilde{2}, \tilde{4}, \tilde{6}, \tilde{8}$ & Intermediate values $(\tilde{x})$ & $(x-1, x, x+1)$ \\
$1 / \tilde{x}$ & Between two adjacent & $(1 /(x+1), 1 / x, 1 /(x-1))$ \\
\hline
\end{tabular}

Step 3: Defuzzifying the fuzzy pair-wise comparison matrices

There are various methods to defuzzify fuzzy numbers. In this paper, we applied the Liou and Wang (1992) s' method to defuzzify fuzzy matrix $\tilde{A}$ into crisp matrix $g_{\alpha, \mu}:$

$g_{\alpha, \mu}\left(\tilde{a}_{i j}\right)=\left[\mu \cdot f_{\alpha}\left(l_{i j}\right)+(1-\mu) \cdot f_{\alpha}\left(u_{i j}\right)\right], 0 \leq \alpha, \mu \leq 1$

$g_{\alpha, \mu}\left(\tilde{a}_{i j}\right)=1 / g_{\alpha, \mu}\left(\tilde{a}_{j i}\right), \quad 0 \leq \alpha, \mu \leq 1: i>j$

$f_{\alpha}\left(l_{i j}\right)=\left(m_{i j}-l_{i j}\right) \cdot \alpha+l_{i j}$ is the left-hand value $\alpha-c u t \quad$ for $\tilde{a}_{i j}$ and $f_{\alpha}\left(u_{i j}\right)=u_{i j}-\left(u_{i j}-m_{i j}\right) \cdot \alpha$ is the right-hand value $\alpha-c u t$ for $\tilde{a}_{i j}$.

The range of uncertainty can be shown by $\alpha$ index. In other words, $\alpha$ index can indicate stable or unstable conditions. The larger value of $\alpha$ index indicates the lower degree of uncertainties. The $\mu$ index can be viewed as the degree of pessimism of a decision maker for the judgment matrix $\tilde{A}^{k}$. The larger value of $\mu$ index indicates the lower degree of optimism (decision maker is pessimistic).

Therefore, the defuzzified pair wise comparison matrix can be expressed as equation (10).

Step 4: Calculating Consistency rate (C.R.) 


$$
\begin{aligned}
& g_{\alpha, \mu}(\tilde{A})=g_{\alpha, \mu}\left(\left[\tilde{a}_{i j}\right]\right)= \\
& \begin{array}{llll}
C_{1} & C_{2} & \ldots & C_{n}
\end{array} \\
& \begin{array}{c}
C_{1} \\
C_{2} \\
\vdots \\
C_{n}
\end{array}\left[\begin{array}{cccc}
1 & g_{\alpha, \mu}\left(\tilde{a}_{12}\right) & \ldots & g_{\alpha, \mu}\left(\tilde{a}_{1 n}\right) \\
1 / g_{\alpha, \mu}\left(\tilde{a}_{12}\right) & 1 & \ldots & g_{\alpha, \mu}\left(\tilde{a}_{2 n}\right) \\
\vdots & \vdots & \ddots & \vdots \\
\left(\tilde{a}_{1 n}\right) & 1 / g_{\alpha, \mu}\left(\tilde{a}_{2 n}\right) & \ldots & 1
\end{array}\right]
\end{aligned}
$$

Saaty (1980) suggests a consistency test to verify conformity of the calculation results. To calculate of consistency rate (C.R.), eigenvalue $\left(\lambda_{\max }\right)$ of the single pair-wise comparison matrix $g_{\alpha, \mu}(\tilde{A})$ should be determined first. $\lambda_{\max }$ is calculated by equation (11).

$$
\operatorname{det}\left(g_{\alpha, \beta}(\tilde{A})-\lambda_{\max }\right)=0
$$

After finding $\lambda_{\max }$, values of consistency index (C.I.) and C.R. can be obtained from equations (12-13):

$$
\begin{aligned}
& \text { C.I. }=\frac{\lambda_{\max }-n}{n-1} \\
& \text { C.R. }=\frac{\text { C.I. }}{\text { R.I. } \cdot_{n}}
\end{aligned}
$$

The value of Random index (R.I.) depends on the value of $n$ and is the average consistency index for randomly generated entries (Saaty, 1980).

Step 5: is C.R. <0.1?

According to Saaty (1980), C.R. $<0.1$ is acceptable scope; otherwise, for the comparison matrix modifications are necessary and new matrix must be solicited.

\section{Step 6: Computing weights of pair-wise comparison matrices, priority weights} for each alternative and making a best decision

The $W$ is the weight of pair-wise comparison matrix $g_{\alpha, \beta}(\tilde{A})$. On the other hand, the $W$ is eigenvector of matrix $g_{\alpha, \beta}(\tilde{A})$ and can be defined as equation (14).

$$
\left[g_{\alpha, \beta}(\tilde{A})-\lambda_{\max }\right] . W=0
$$

After calculating the weights for all pair-wise comparison matrices of the proposed hierarchical structure, in this step the final weight of the alternatives can be calculated and then the best decision made. The weights can be sorted decreasingly and the best alternative is selected finally. 


\section{Experiment and Results}

In this section, the proposed methodology is implemented on an actual case in one of the biggest provinces (Kerman province) in Iran to select the best location for construction of an underground dam. Following successive droughts in the province and the benefits of underground dams in utilization of unconventional waters, the expert team suggested several options for selecting and evaluating the best location for building the underground dam Construction in the city of Rafsanjan. Figure 2 shows position of selected options over the city of Rafsanjan. Selection of the best location should be done based on criteria in such a way that all important technical factors are considered. The best location for underground dam construction can provide appropriate amount of water for agriculture in this region.

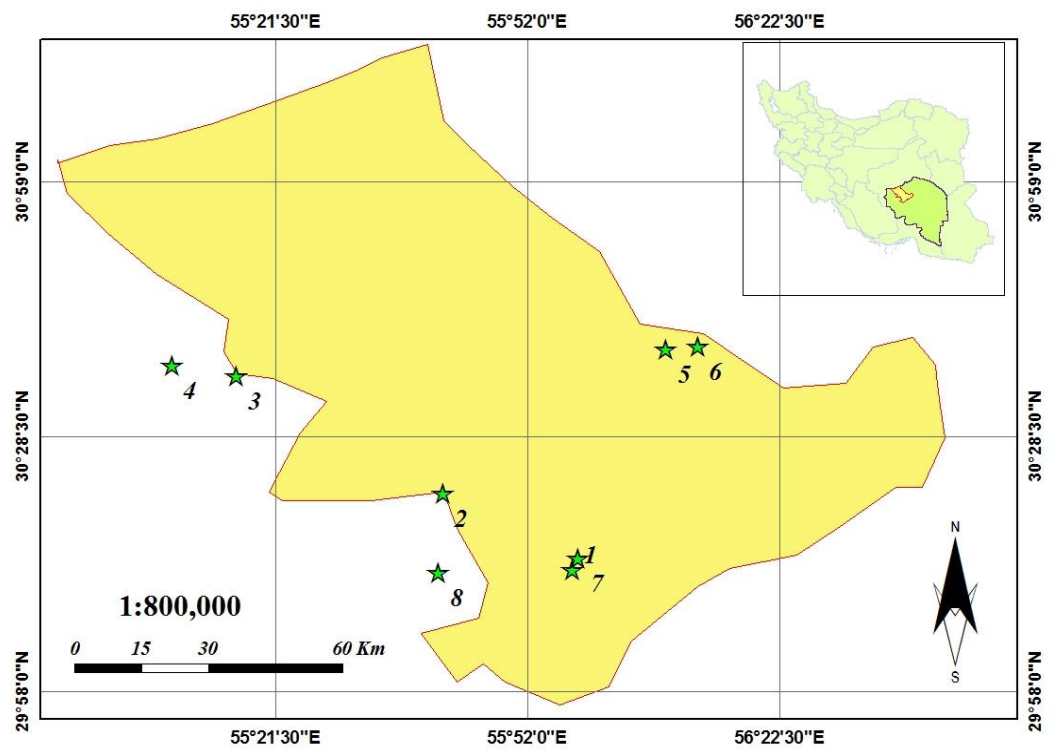

Figure 2

The position of 8 selected locations over Rafsanjan city and the Kerman province

The steps of the proposed methodology to select the best location for underground dam construction are described as follows:

\section{Step1: Determining criteria and alternatives and establish hierarchal structure}

The expert team should firstly determine the related criteria to evaluate the alternatives. The criteria and alternatives should be able to describe the existing difficult decision problem. Thus, considering these criteria and alternatives are very important for the decision makers' team in selecting the best location for underground dam construction. 
The selected criteria according to the methodology of studying the physical specifications are as follows: bed width, utilization land area, distance to utilization location, bed slope, wall material which are extracted from the topographical maps. The, data are evaluated by experts and field studies to ensure the precision of data. After final approval, the proposed methodology is used to select the best location of project and its priorities.

Each criterion used for priority setting of a location has optimal values and conditions which should be met. For the slope, if it is high, it causes ejection of reserved water in the reservoir and thus water accumulation on its surface which, in turn, leads to subsequent problems. On the other hand, very low slope causes that there is a long distance when the reserved water is transferred and when it is transferred from the depth to the bed. Therefore, the best slope for selecting an option is about $-12 \%$ (Nilsson, 1988). The minimum width is the most appropriate bed width. Of course, the less this width is, fewer water will be reserved. Thus, here it is assumed that bed width does not influence on the upstream reservoir. The third important factor is the wall material. The stronger and more impenetrable the walls are (and have fewer seams and cracks), the more appropriate they are considered. The stratification direction is also important which should be perpendicular to the flow. Another criterion is the distance between water extraction location and water utilization location. If this distance is shorter, construction cost will be lower. The last criterion is the area of agricultural lands which need using accumulated water in the dam. If the area of lands is large, justification for dam construction will be more logical. Related matrixes were built and calculations were performed following converting amounts of criteria intro measurable values.

After reviewing the literature related criteria, the experts' team considered eight candidate locations to evaluate with regard the expert's judgment who had worked in related field. Finally, the eight candidates are Goor choopan (Alternative 1), Khezr (Alternative 2), Bayaz (Alternative 3), Tezerj (Alternative 4), Uderj (Alternative 5), Joz (Alternative 6), Givdari (Alternative 7), and Dahaneh abolfazl (Alternative 8). The position of eight candidates over the city of Rafsanjan and Kerman province are shown in Figure 2.

After determining the criteria and alternatives, decision makers will setup hierarchical structure. The hierarchical structure should be able to break the existing complex decision problem into manageable components of different layers/levels (Nazari-Shirkouhi et al., 2011). The selected criteria can determine the levels of hierarchical structure. Level \#1 (target level) addresses target (selecting the best location for underground dam construction). Level \#2 (criterion level) addresses different factors impacting on locating decisions for underground dam construction. In the present paper, five criteria are considered. Finally, the latter level usually consists of alternatives. Different levels of the hierarchy structure for locating the underground dam construction are sketched in Figure 3. 


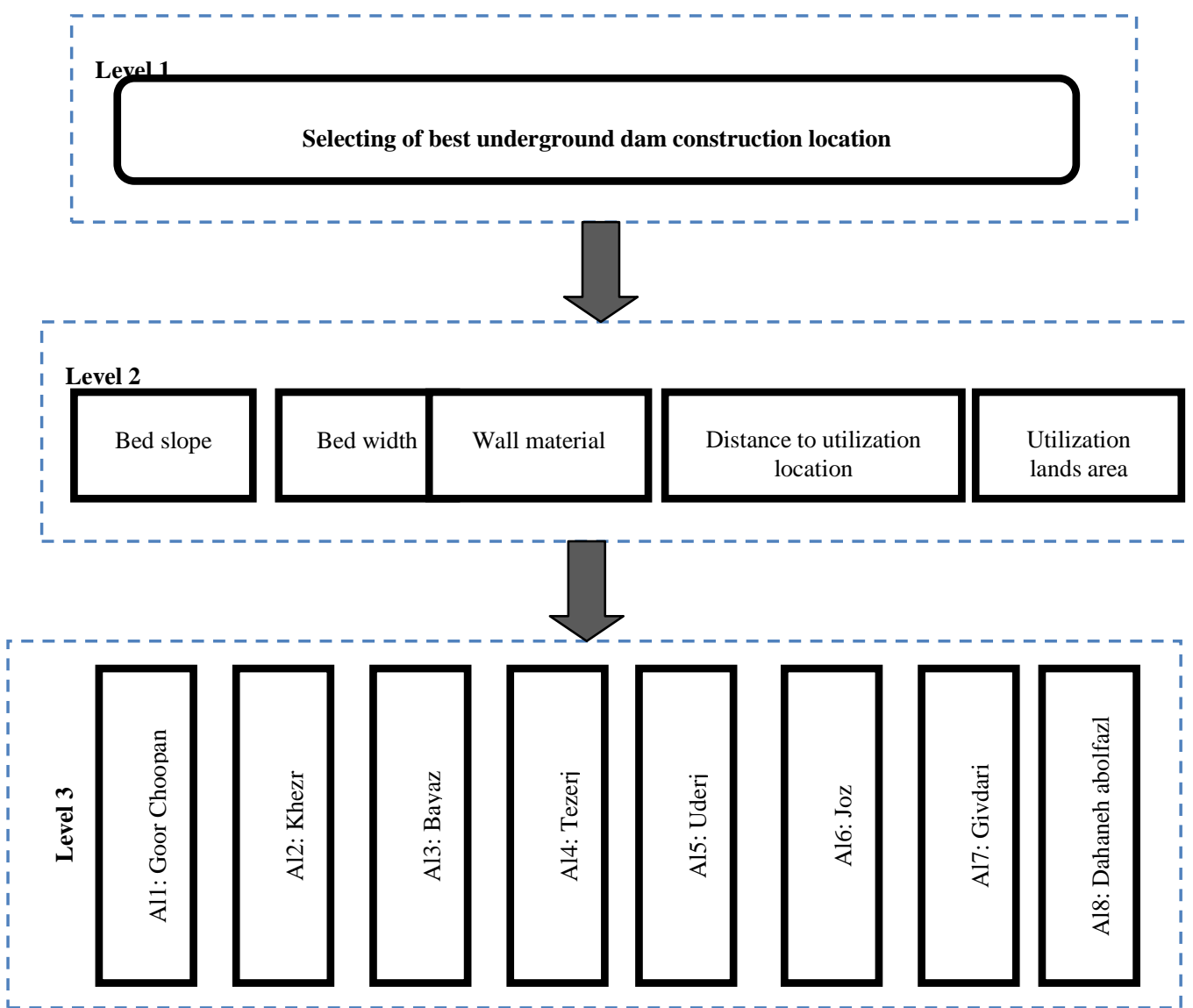

Figure 3

Hierarchical structure for underground dam construction

Step 2: Collecting experts' judgments based on fuzzy scale and establish fuzzy pair-wise comparison matrices

Because the problem of locating underground dam construction can be modeled based on expert's judgment, experts play an important role on the reliability and accuracy of evaluating locations of underground dam construction. In this case study, the project manager decided to consider the problem of underground dam construction depending on the judgments by seven experts.

The sample questionnaire (see Nazari-Shirkouhi et al., 2011) is applied to find the weights of the criteria using experts' judgments in the form of fuzzy numbers shown in Table 1. According to the linguistic scale, underlying TFN in Table 1 and equations (4-7), the fuzzy decision matrix for criteria with respect to goals are achieved from a questionnaire filled by experts. Then, the fuzzy decision matrices 
are converted to fuzzy numbers in a way explained in Azadeh et al. (2011) and Nazari-Shirkouhi et al. (2011). Table 2 shows the aggregated fuzzy decision matrix of criteria (level 2).

Table 2

Aggregated fuzzy comparison of criteria (level 2) with respect to goal

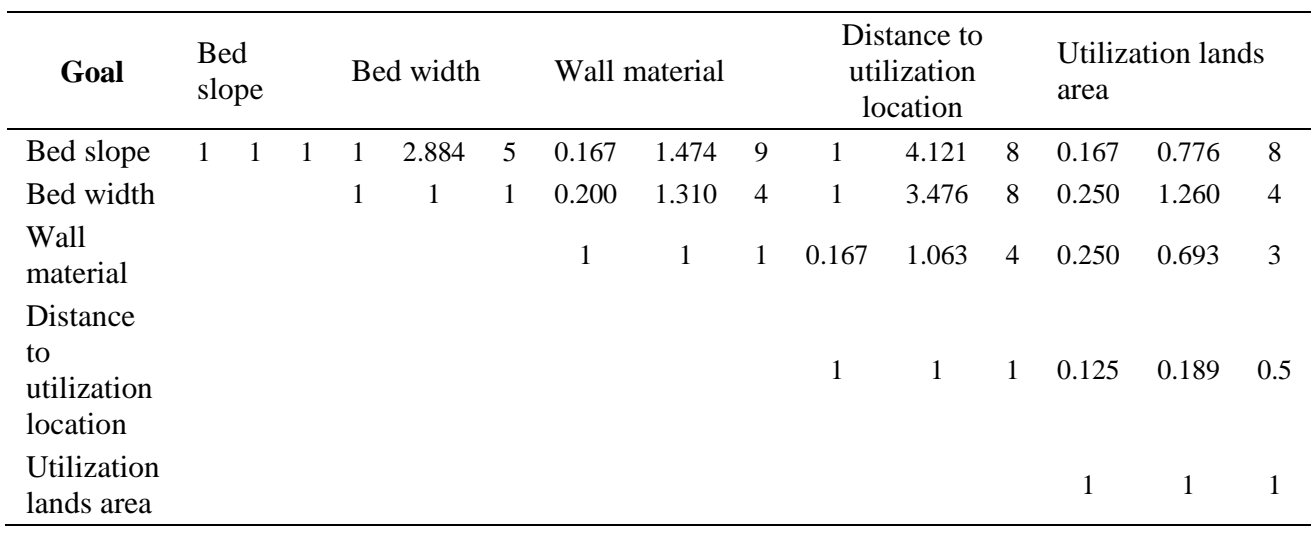

Step 3: Defuzzifying the fuzzy pair-wise comparison matrices

After making the fuzzy matrices for all levels, the matrices are defuzzified. Using equations (8-9) and setting $\alpha$ and $\mu$ to 0.5 , the final defuzzified matrix (Table 2) is shown in Table 3 .

Table 3

Defuzzified matrix of criteria (level 2) with respect to goal

\begin{tabular}{lccccc}
\hline \multicolumn{1}{c}{ Goal } & Bed slope & $\begin{array}{l}\text { Bed } \\
\text { width }\end{array}$ & $\begin{array}{l}\text { Wall } \\
\text { material }\end{array}$ & $\begin{array}{c}\text { Distance to } \\
\text { utilization } \\
\text { location }\end{array}$ & $\begin{array}{c}\text { Utilization } \\
\text { lands area }\end{array}$ \\
\hline Bed slope & 1 & 2.942 & 3.029 & 4.311 & 2.4296 \\
$\begin{array}{l}\text { Bed width } \\
\text { Wall material }\end{array}$ & 0.340 & 1 & 1.705 & 3.988 & 1.6925 \\
$\begin{array}{l}\text { Distance to } \\
\text { utilization }\end{array}$ & 0.330 & 0.586 & 1 & 1.573 & 1.1592 \\
$\begin{array}{l}\text { location } \\
\text { Utilization }\end{array}$ & 0.232 & 0.251 & 0.636 & & \\
lands area & 0.412 & 0.591 & 0.863 & & \\
\hline
\end{tabular}

Step 4: Calculating Consistency rate (C.R.)

The consistencies of fuzzy judgment matrices are evaluated using equations (1213). Equation (11) is used to determine the maximum eigenvalue $\left(\lambda_{\max }\right)$. After solving $\lambda_{\max }$ equals to 5.1703 . 
Step 5: is C.R. $<0.1$ ?

The results indicate that C.R. is lower than 0.1 and the decision matrix for the second level of the hierarchical structure is consistent. The C.R.s of all the matrices are below 0.1 which show their consistency.

Step 6: Computing weights for pair-wise comparison matrices, priority weights for each alternative and making a best decision

After solving equation (14), weights of the five criteria in level $2(W)$ are shown in Table 4.

Table 4

The weights of five criteria of level 2

\begin{tabular}{cccccc}
\hline Criteria & $\begin{array}{c}\text { Bed } \\
\text { slope }\end{array}$ & $\begin{array}{c}\text { Bed } \\
\text { width }\end{array}$ & $\begin{array}{c}\text { Wall } \\
\text { material }\end{array}$ & $\begin{array}{c}\text { Distance to utilization } \\
\text { location }\end{array}$ & $\begin{array}{c}\text { Utilization lands } \\
\text { area }\end{array}$ \\
\hline Weight & 0.4163 & 0.219 & 0.1344 & 0.0667 & 0.1636 \\
\hline
\end{tabular}

Table 5

Summaries of results for level 2 to level 3

\begin{tabular}{|c|c|c|c|c|c|c|c|c|c|}
\hline \multirow[b]{2}{*}{ Criteria } & \multirow[b]{2}{*}{$\begin{array}{c}\text { Weights } \\
\text { for } \\
\text { level } 2\end{array}$} & \multicolumn{8}{|c|}{ Weights for level 3} \\
\hline & & 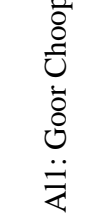 & 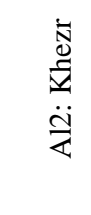 & 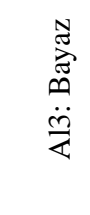 & 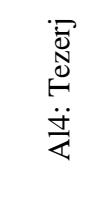 & $\begin{array}{l}\overrightarrow{\bar{d}} \\
\stackrel{D}{D} \\
\ddot{n} \\
\ddot{z}\end{array}$ & 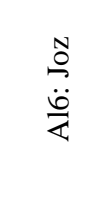 & 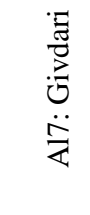 & 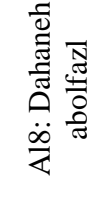 \\
\hline Bed slope & 0.4163 & 0.1649 & 0.2017 & 0.1264 & 0.0309 & 0.1261 & 0.1006 & 0.1612 & 0.0883 \\
\hline Bed width & 0.219 & 0.1451 & 0.0755 & 0.0956 & 0.2179 & 0.182 & 0.1406 & 0.0259 & 0.1175 \\
\hline $\begin{array}{c}\text { Wall } \\
\text { material }\end{array}$ & 0.1344 & 0.1968 & 0.1892 & 0.0619 & 0.1597 & 0.1878 & 0.0718 & 0.0891 & 0.0437 \\
\hline $\begin{array}{l}\text { Distance } \\
\text { to } \\
\text { utilization } \\
\text { location }\end{array}$ & 0.0667 & 0.1695 & 0.1714 & 0.0202 & 0.1714 & 0.0905 & 0.042 & 0.1675 & 0.1675 \\
\hline $\begin{array}{l}\text { Utilization } \\
\text { lands area }\end{array}$ & 0.1636 & 0.1974 & 0.1898 & 0.0617 & 0.1482 & 0.1885 & 0.0721 & 0.0985 & 0.0438 \\
\hline \multicolumn{2}{|c|}{ Final Weight } & 0.0132 & 0.0127 & 0.0041 & 0.0099 & 0.0126 & 0.0048 & 0.0066 & 0.0029 \\
\hline
\end{tabular}

The local weights of the alternatives are calculated using equation (14). The final weights of all alternatives are shown in Table 5. The final weights of the alternatives using data of Table 5 are as follows: 0.0132, 0.0127, 0.0041, 0.0099, $0.0126,0.0048,0.0066$, and 0.0029 for $\mathrm{Al}_{1}$ to $\mathrm{Al}_{8}$, respectively. 
According to results, the first alternative has the highest weight and is the most proper location according to the experts' judgment in the fuzzy environment. "Goor Choopan" and "Dahaneh abolfazl" locations are suggested as the first and last options, respectively.

\section{Validation and Verification}

For validation and verification of results, the pair-wise comparison matrices are run in the crisp state (standard AHP). The local weights of criteria in the second hierarchical level (AHP) are shown in Table 6.

Table 6

The weights of five criteria of level 2 (AHP)

\begin{tabular}{cccccc}
\hline Criteria & $\begin{array}{c}\text { Bed } \\
\text { slope }\end{array}$ & $\begin{array}{c}\text { Bed } \\
\text { width }\end{array}$ & $\begin{array}{c}\text { Wall } \\
\text { material }\end{array}$ & $\begin{array}{c}\text { Distance to utilization } \\
\text { location }\end{array}$ & $\begin{array}{c}\text { Utilization lands } \\
\text { area }\end{array}$ \\
\hline Weight & 0.42 & 0.22 & 0.12 & 0.06 & 0.16 \\
\hline
\end{tabular}

Table 7

Summaries of results (AHP)

\begin{tabular}{|c|c|c|c|c|c|c|c|c|c|}
\hline \multirow[b]{2}{*}{ Criteria } & \multirow[b]{2}{*}{$\begin{array}{l}\text { Weights } \\
\text { for } \\
\text { level } 2\end{array}$} & \multicolumn{8}{|c|}{ Weights for level 3} \\
\hline & & 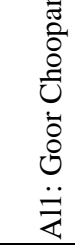 & 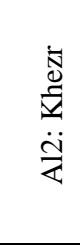 &  & 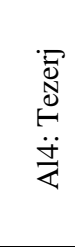 & $\begin{array}{l}\overrightarrow{\bar{d}} \\
\vec{D} \\
\ddot{n} \\
\dot{z}\end{array}$ & $\begin{array}{l}\stackrel{N}{O} \\
\stackrel{0}{4}\end{array}$ & $\begin{array}{l}\vec{\Xi} \\
\stackrel{\Xi}{Z} \\
\dot{U} \\
\ddot{\bar{\Delta}}\end{array}$ & 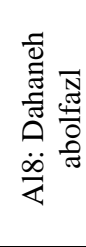 \\
\hline Bed slope & 0.42 & 0.17 & 0.20 & 0.13 & 0.02 & 0.13 & 0.09 & 0.17 & 0.09 \\
\hline Bed width & 0.22 & 0.13 & 0.07 & 0.09 & 0.23 & 0.19 & 0.15 & 0.03 & 0.12 \\
\hline Wall material & 0.12 & 0.20 & 0.20 & 0.06 & 0.14 & 0.20 & 0.07 & 0.09 & 0.04 \\
\hline $\begin{array}{c}\text { Distance to } \\
\text { utilization } \\
\text { location }\end{array}$ & 0.06 & 0.16 & 0.17 & 0.02 & 0.17 & 0.10 & 0.04 & 0.17 & 0.17 \\
\hline $\begin{array}{c}\text { Utilization lands } \\
\text { area }\end{array}$ & 0.16 & 0.20 & 0.20 & 0.06 & 0.14 & 0.20 & 0.07 & 0.09 & 0.04 \\
\hline \multicolumn{2}{|c|}{ Final Weight } & 0.167 & 0.170 & 0.092 & 0.112 & 0.161 & 0.094 & 0.111 & 0.088 \\
\hline
\end{tabular}


As we can see in Table 4 and Table 6), the criterion 1 (Bed slope) and the criterion 4 (Distance to utilization location) are the most important and least important criteria according to their weights in both AHP and Fuzzy AHP methods, respectively. The final weights of all alternatives (AHP) are shown in Table 7.

The results of two runs (fuzzy AHP and AHP) have been compared and shown in Table 8.

Table 8

Comparison of ranks between AHP and Fuzzy AHP

\begin{tabular}{lcccc}
\hline \hline \multirow{2}{*}{ Alternatives } & \multicolumn{2}{c}{ AHP } & \multicolumn{2}{c}{ Fuzzy AHP } \\
\cline { 2 - 5 } & Weight & Rank & Weight & Rank \\
\hline Al1: Goor Choopan & 0.167 & 2 & 0.0132 & 1 \\
Al2: Khezr & 0.17 & 1 & 0.0127 & 2 \\
Al3: Bayaz & 0.092 & 7 & 0.0041 & 7 \\
Al4: Tezerj & 0.112 & 4 & 0.0099 & 4 \\
Al5: Uderj & 0.161 & 3 & 0.0126 & 3 \\
A16: Joz & 0.094 & 6 & 0.0048 & 6 \\
Al7: Givdari & 0.111 & 5 & 0.0066 & 5 \\
Al8: Dahaneh abolfazl & 0.088 & 8 & 0.0029 & 8 \\
\hline \hline
\end{tabular}

After ranking the alternatives in two states of AHP and Fuzzy AHP, the only difference is in ranks 1 and 2. In AHP method, the fist alternative (Khezr) is the best location and in the fuzzy AHP method, the second alternative (Goor Choopan) is the best underground dam construction location. As we can observe in the Table 8 not only all weights have changed but also the ranks of alternatives (locations) have changed. Using fuzzy theory for selecting the best location for underground dam construction can reduce vagueness and uncertainty that are inherent in problem.

\section{Conclusion}

In this paper, a holistic fuzzy AHP approach was proposed as a multi criteria decision making tool for evaluating and selecting the best location of underground dam construction Fuzzy sets theory was applied for selecting the best location of underground dam construction to reduce ambiguities and uncertainties inherent in the selection criteria. Bed slope, bed width, wall material, distance to utilization location, and utilization lands area were considered as the criteria. Eighth different alternatives for the location underground dam construction were considered in an actual case study. Based on the goal of underground dam construction, the proposed hierarchical structure may vary slightly. Finally an experiment and actual case has been conducted to apply the proposed methodology in evaluating and selecting the best underground dam construction location as a case by using judgments of six experts who had worked in the underground dam construction field and then the results were represented. As a result of the empirical study, we found that the fuzzy AHP is practical and holistic approach for ranking the 
candidates in terms of their overall performance regarding multiple criteria. In this case, fuzzy AHP provides a very useful decision-making tool to rank underground dam construction locations. It is expected that the present paper will serve as guideline for future studies and applications of locating in underground dam construction. Also, the proposed approach can be applied for other regions.

\section{Acknowledgement}

Special thanks go to Watershed Research Center, Agriculture and Natural Resources Division of the Kerman Province for cooperation in preparing this paper. In addition, helps by Ms. Haj-Seyyed-Alikhani, expert in Watershed Research Center for preparing related maps are also highly appreciated.

\section{References}

[1] Akpinar, N., Talay, I., \& Gun, S. (2005). Priority Setting in Agricultural Land-Use Types for Sustainable Development. Renewable Agriculture and Food Systems, 20(03), 136-147

[2] Alias, M. A., Hashim, S. Z. M., \& Samsudin, S. (2009). Using Fuzzy Analytic Hierarchy Process for Southern Johor River Ranking. Int J Adv Soft Comp Appl, 1(1), 62-76

[3] Anagnostopoulos, K. P., Gratziou, M., \& Vavatsikos, A. P. (2007). Using the Fuzzy Analytic Hierarchy Process for Selecting Wastewater Facilities at Prefecture Level. Journal of European Water, 19(20), 15-24

[4] Anagnostopoulos, K. P., Petalas, C., \& Pisinaras, V. (2005). Water Resources Planning Using The Ahp And Promethee Multicriteria Methods: The Case Of Nestos River-Greece. The $7^{\text {th }}$ Balkan Conference on Operational Research (BACOR 00), Constanta, May 2000, Romania

[5] Ascough, J. C., Maier, H. R., Ravalico, J. K., \& Strudley, M. W. (2008). Future Research Challenges for Incorporation of Uncertainty in Environmental and Ecological Decision-Making. ecological modelling, 219(3-4), 383-399

[6] Azadeh, A., Nazari-Shirkouhi, S., Hatami-Shirkouhi, L., \& Ansarinejad, A. (2011). A Unique Fuzzy Multi-Criteria Decision Making: Computer Simulation Approach for Productive Operators' Assignment in Cellular Manufacturing Systems with Uncertainty and Vagueness. The International Journal of Advanced Manufacturing Technology, 56(1), 329-343

[7] Azadeh, A., Shirkouhi, S. N., \& Rezaie, K. (2010). A Robust DecisionMaking Methodology for Evaluation and Selection of Simulation Software package. The International Journal of Advanced Manufacturing Technology, 47(1), 381-393

[8] Buckley, J. J. (1985). Fuzzy Hierarchical Analysis. Fuzzy sets and systems, 17(3), 233-247 
[9] Garagunis, C. N. (1981). Construction of an impervious diaphragm for improvement of a subsurface water-reservoir and simultaneous protection from migrating salt water. Bulletin of Engineering Geology and the Environment, 24(1), 169-172

[10] Gupta, R. N., Mukherjee, K. P., \& Singh, B. (1987). Design of underground artificial dams for mine water storage. Mine Water and the Environment, 6(2), 1-14

[11] Iranmanesh, H., Shirkouhi, S. N., \& Skandari, M. R. (2008). Risk evaluation of information technology projects based on fuzzy analytic hierarchal process. International Journal of Computer and Information Science and Engineering, 2(1), 38-44

[12] Kaufmann, A., \& Gupta, M. M. (1988). Fuzzy mathematical models in engineering and management science. Elsevier Science Inc, Netherlands

[13] Kong, F., \& Liu, H. (2005). Applying fuzzy Analytic Hierarchy Process to evaluate success factors of e-commerce. International Journal of Information and Systems Sciences, 1(3-4), 406-412

[14] Li, L., Shi, Z. H., Yin, W., Zhu, D., Ng, S. L., Cai, C. F., \& Lei, A. L. (2009). A fuzzy analytic hierarchy process (FAHP) approach to ecoenvironmental vulnerability assessment for the danjiangkou reservoir area, China. Ecological Modelling, 220(23), 3439-3447

[15] Liou, T. S., \& Wang, M. J. J. (1992). Ranking fuzzy numbers with integral value. Fuzzy sets and systems, 50(3), 247-255

[16] Mei, X., Rosso, R., Huang, G. L., \& Nie, G. S. (1989). Application of analytical hierarchy process to water resources policy and management in Beijing, China. Closing the Gap between Theory and Practice, Proceedings of the Baltimore Symposium, IAHS Publ., pp.73-83

[17] Montazar, A., \& Behbahani, S. M. (2007). Development of an optimised irrigation system selection model using analytical hierarchy process. Biosystems Engineering, 98(2), 155-165

[18] Montazar, A., \& Zadbagher, E. (2010). An analytical hierarchy model for assessing global water productivity of irrigation networks in Iran. Water resources management, 24(11), 2817-2832

[19] Nazari-Shirkouhi, S., Ansarinejad, A., Miri-Nargesi, S., Dalfard, V. M., \& Rezaie, K. (2011). Information Systems Outsourcing Decisions Under Fuzzy Group Decision Making Approach. International Journal of Information Technology \& Decision Making (IJITDM), 10(06), 989-1022

[20] Nilsson, A. (1988). Groundwater dams for small-scale water supply, Intermediate Technology Publications Ltd. London, pp. 69

[21] Okada, H., Styles, S. W., \& Grismer, M. E. (2008). Application of the Analytic Hierarchy Process to irrigation project improvement: Part II. How 
professionals evaluate an irrigation project for its improvement. Agricultural Water Management, 95(3), 205-210

[22] Onder, H. and yilmaz, M. (2000). Underground dams: A tool of sustainable development and management of groundwater resources. European Water, 11(12), 30-40

[23] Opricovic, S. (2011). Fuzzy VIKOR with an application to water resources planning. Expert Systems with Applications, 38(10), 12983-12990

[24] Pilavachi, P. A., Chatzipanagi, A. I., \& Spyropoulou, A. I. (2009). Evaluation of hydrogen production methods using the Analytic Hierarchy Process. International Journal of hydrogen energy, 34(13), 5294-5303

[25] Saaty, T. L. (1980). The analytic hierarchy process. 1980. McGraw-Hill, New York

[26] Shaw, K., Shankar, R., Yadav, S. S., \& Thakur, L. S. (2012). Supplier selection using fuzzy AHP and fuzzy multi-objective linear programming for developing low carbon supply chain. Expert Systems with Applications, 39(9), 8182-8192

[27] Srdjevic, B. (2007). Linking analytic hierarchy process and social choice methods to support group decision-making in water management. Decision Support Systems, 42(4), 2261-2273

[28] Srdjevic, B., \& Medeiros, Y. D. P. (2008). Fuzzy AHP assessment of water management plans. Water Resources Management, 22(7), 877-894

[29] Stirn, L. (2006). Integrating the fuzzy analytic hierarchy process with dynamic programming approach for determining the optimal forest management decisions. Ecological modelling, 194(1), 296-305

[30] Takács, M. (2010). Multilevel Fuzzy Approach to the Risk and Disaster Management. Acta Polytechnica Hungarica, 7(4), 91-102

[31] Tsiko, R. G., \& Haile, T. S. (2011). Integrating Geographical Information Systems, Fuzzy Logic and Analytical Hierarchy Process in Modelling Optimum Sites for Locating Water Reservoirs. A Case Study of the Debub District in Eritrea. Water, 3(1), 254-290

[32] Vahidnia, M. H., Alesheikh, A., Alimohammadi, A., \& Bassiri, A. (2008). Fuzzy analytical hierarchy process in GIS application. The International Archives of the Photogrammetry, Remote Sensing and Spatial Information Sciences, 37, 593-596

[33] Wang, X., Chan, H. K., Yee, R. W. Y., \& Diaz-Rainey, I. (2012). A twostage fuzzy-AHP model for risk assessment of implementing green initiatives in the fashion supply chain. International Journal of Production Economics, 135(2), 595-606

[34] Zadeh, L. A. (1965). Fuzzy sets. Information and control, 8(3), 338-353 
[35] Zheng, G., Zhu, N., Tian, Z., Chen, Y., \& Sun, B. (2012). Application of a trapezoidal fuzzy AHP method for work safety evaluation and early warning rating of hot and humid environments. Safety Science, 50(2), 228239 